\title{
Superconducting AC Homopolar Machines for High-Speed Applications
}

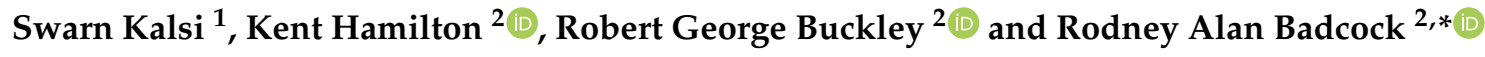 \\ 1 Kalsi Green Power Systems; Princeton, NJ 08540, USA; skalsi@KalsiGPS.com \\ 2 Robinson Research Institute, Victoria University of Wellington, PO Box 33436, Lower Hutt 5046, \\ New Zealand; kent.hamilton@vuw.ac.nz (K.H.); bob.buckley@vuw.ac.nz (R.G.B.) \\ * Correspondence: Rod.Badcock@vuw.ac.nz; Tel.: +64-4463-3714
}

Received: 5 October 2018; Accepted: 25 December 2018; Published: 28 December 2018

\begin{abstract}
This paper presents a novel high-speed alternating current (AC) homopolar motor/generator design using stationary ReBCO excitation windings. Compact, lightweight, high-efficiency motors and generators are sought for a multitude of applications. AC homopolar synchronous machines are an ideal choice for such applications as these machines enable very high rotational frequencies. These machines include both AC armature winding and direct current (DC) excitation winding within the stationary part of the machine. The stationary excitation winding magnetizes a solid steel rotor, enabling operating speeds limited only by the mechanical stress limit of the rotor steel. The operating speeds are many multiples of conventional power $50 / 60 \mathrm{~Hz}$ machines. Significant cooling requirements limit machines of this type utilizing copper excitation windings to only a few kilowatts. However, megawatt ratings become possible when superconductor coils are used. This paper describes the design and analysis of an AC homopolar machine in the context of developing a $500 \mathrm{~kW}$ flywheel system to be used for energy recovery and storage in commuter rail subway systems. Different approaches are discussed for an AC armature employing conventional copper coils. Challenges of building and cooling both armature and field coils are discussed and preferred approaches are suggested. Calculations of the machine performance are then made.
\end{abstract}

Keywords: superconducting machines; superconductors; high-speed machines; AC homopolar machines; energy storage; flywheel energy storage

\section{Introduction}

The power of an electrical machine is proportional to both its rotor excitation field and rotational speed. Thus in order to achieve high-power density machines, both magnetic field and rotational speeds must be as large as possible. Speeds above 15,000 rpm are not possible with active coils attached to the rotor due to excessive centrifugal stresses, challenges of handling power, and cooling system interfaces. Additionally, copper windings cannot feasibly produce magnetic fields above $\sim 1.5 \mathrm{~T}$, so higher fields require superconducting coils [1]. A recent review [2] shows demonstrations of superconducting machines up to 10,000 RPM, with high-temperature superconductor (HTS) rotors demonstrated to 15,000 RPM.

Machines employing permanent magnets (PM) on the rotor have been built for high speed applications. However, in such machines, PM are held on the rotor with a structural support. The permissible rotor speed is limited by the constraints of the structural support. For example, [3] describes a PM machine rated $45 \mathrm{~kW}$ at 32,000 RPM but its diameter is limited to $92 \mathrm{~mm}$. However, the AC homopolar machine described in this paper is rated $500 \mathrm{~kW}$ at 25,000 RPM and a rotor diameter of $200 \mathrm{~mm}$. Our rotor made of a single material-the rotor speed is only limited 
by centrifugal stresses in the rotor material. It is possible to achieve much larger machine with a rotor made of a single solid material.

The recent emergence of commercially produced HTS wire has radically changed both the cost-metric and technical viability of superconducting machines [4]. HTS wires are superconducting at temperatures up to $93 \mathrm{~K}$, enabling mechanical refrigerators to be used in conjunction with gas-exchange cooling. This eliminates many of the problems associated with rotating liquid cryogens, whilst the elevated operating temperature provides 'thermal head-room', further enhancing system stability. As a result, novel HTS generators and motors are currently a subject of hot global interest $[5,6]$.

The key objectives are achieving compact and lightweight devices of the highest possible torque/weight and electrical efficiencies [7]. One typical application powers electric aircraft propulsion fans with energy generated from on-board generators directly coupled to high-speed gas turbines [8]. A second application is machines which act as both motor and generator integrated with high-speed flywheels for energy storage [9]. This system could be employed in transit systems as a method of fast energy recovery and delivery. Either on moving assets such as buses, or at stationary transport nodes such as subway stations $[10,11]$. Alternately, the flywheel energy storage device could act as a battery for storing surplus solar and wind energy for later use during lean periods of energy generation $[12,13]$.

HTS exciter coils enable realizing compact and light-weight machines. An alternating current (AC) homopolar synchronous machine topology [14,15] enables high rotational speeds achieved by removing the requirement for active rotating coils, making it ideal for high power applications. Building such a machine using conventional copper excitation coils presents significant cooling challenges and limits the size of such a machine to a power rating of only a few kilowatts. However, megawatt rated machines become possible by replacing the direct current (DC) field excitation coil with a suitable superconducting coil.

This paper describes design and analysis for machines employing a HTS DC excitation coil. Different approaches are discussed for building AC armature coils using conventional copper coil technologies. Challenges of building and cooling both armature and field coils are discussed, and possible approaches are suggested for handing them. The application example used is a stationary fast energy storage system for use in subway systems, however, much of what is discussed here is applicable for airborne applications such as those studied by Sivasubramaniam [16]. The machine described in this reference was designed for aerospace application with intention of keeping size and mass as small as possible, whereas the current machine is being designed for on ground application to mate with a flywheel for energy storage. An electromagnetic shield (Figure 3) has been incorporated for reducing $\mathrm{AC}$ losses in the superconducting coil and minimizing refrigerator cooling power.

\section{Application Requirements}

In order to describe the design process, a flywheel energy storage application is selected for storing $9 \mathrm{MJ}$ of kinetic energy. This electric motor/generator machine coupled to a flywheel is rated at $500 \mathrm{~kW}$. Its requirements are summarized in Table 1.

Table 1. Requirements for a flywheel energy storage device employing AC homopolar motor/generator.

\begin{tabular}{cc}
\hline Parameter & Value \\
\hline Energy storage capability, MJ & 9 \\
Rotating machine power rating, kVA & 500 \\
Rotary speed, RPM & 25,000 \\
Line voltage, $\mathrm{V}$ & 866 \\
Rotor diameter, $\mathrm{mm}$ & $<200$ \\
Axial length of stator, $\mathrm{mm}$ & $<500$ \\
Axial length of rotor, $\mathrm{mm}$ & $<420$ \\
Overall stator coil current density, A/mm ${ }^{2}$ & $<3.0$ \\
Maximum flux density in stator laminations, T & $<1.5$ \\
\hline
\end{tabular}


This machine is designed using the following assumptions:

- The rotating machine is synchronous AC homopolar type with four poles;

- The field winding is located on the stator and is made from HTS; either rare-earth-barium-copper-oxide (ReBCO), or di-bismuth-strontium-calcium-copper-oxide (DI-BSCCO);

- The operating temperature for HTS windings in $50 \mathrm{~K}$ for ReBCO and $30 \mathrm{~K}$ for DI-BSCCO;

- The field winding is cooled using a suitable cryocooler available off-the-shelf;

- The armature on the stator is a three-phase winding employing a suitable Litz copper wire cable;

- The armature coils have current densities; $3 \mathrm{~A} / \mathrm{mm}^{2}$ (overall cross-section including cooling tube) and $6 \mathrm{~A} / \mathrm{mm}^{2}$ (in copper);

- The armature winding is liquid cooled;

- $\quad$ The rotor is made of high-permeability Aermet 310 [17] magnetic steel; and

- The stator laminations are $0.1 \mathrm{~mm}$ thick JFE Steel Corporation, Chiba, Japan JNEX-Core (model 10JNEX900) intended to reduce iron losses.

\section{Machine Configuration}

A cutaway diagram of the AC homopolar motor/generator is shown in Figure 1. The shaft and rotor have not been sectioned so as to show the four-pole layout, with $90^{\circ}$ rotationally offset poles. The three armature coil colors illustrate the three phases winding scheme. The HTS coil cryostat and its surrounding insulation have been omitted for clarity, as has an electromagnetic (EM) shield located between the armatures and the superconducting coils. The ferromagnetic poles are shaped as in any salient pole machine so as to reduce harmonic and torque ripple to acceptable levels, as described in the next section.

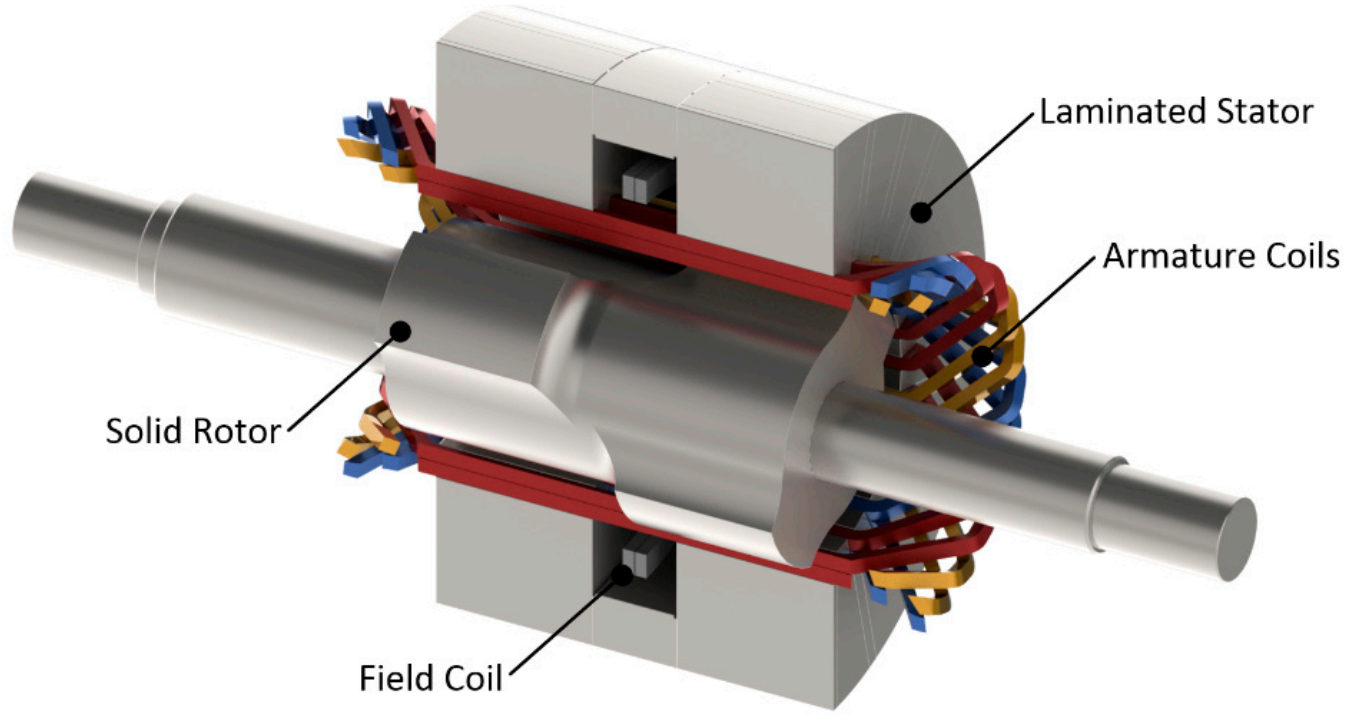

Figure 1. Sectioned view of the AC homopolar motor/generator.

In the flywheel energy storage system, the homopolar motor/generator is located between two glass fiber reinforced polymer flywheels as shown in Figure 2. This arrangement reduces the required shaft size by halving the power transferred through any one part of the shaft. This assembly is housed in a vacuum chamber, with the rotating components supported only by magnetic levitating bearings, enabling operation up to 25,000 RPM. At the high rotational speed desired, housing the system in a vacuum is required to reduce windage friction that would otherwise result in high drag. Frictionless non-contact magnetic bearings are also required as mechanical bearings would not be able to operate continuously due to frictional losses and wear [18]. 


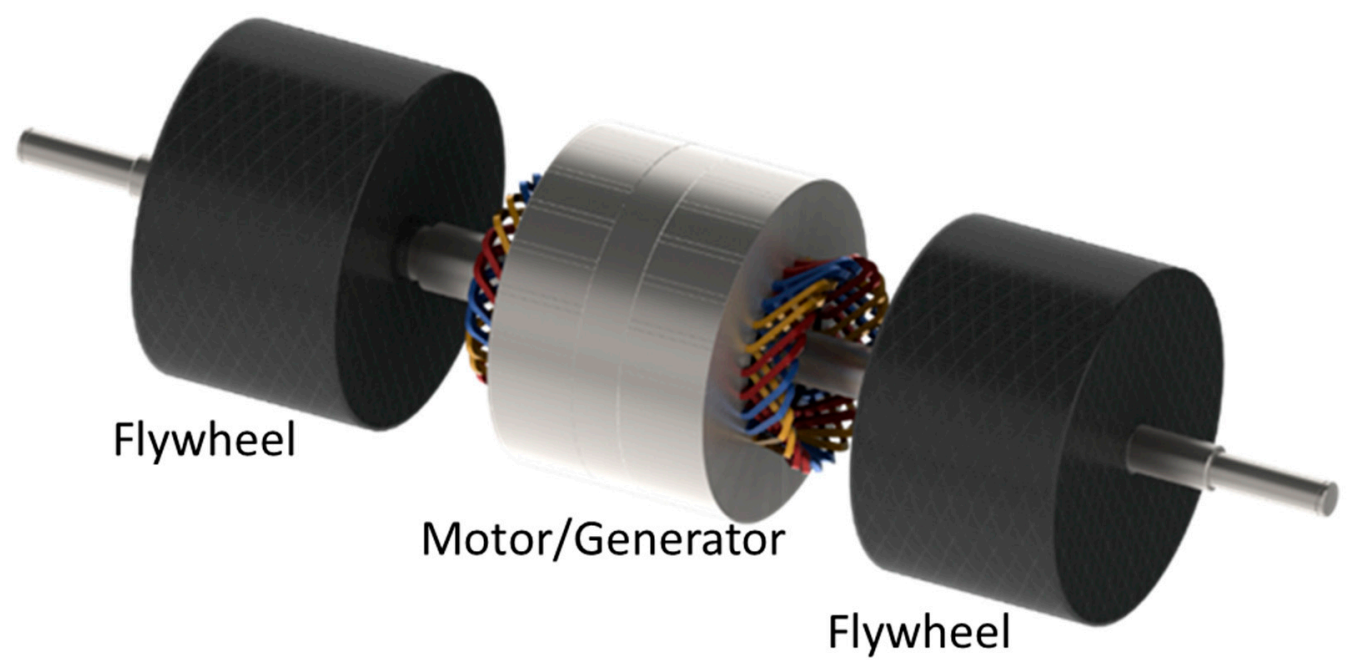

Figure 2. Flywheel energy storage system incorporating a superconducting motor/generator.

The design of the flywheels, vacuum chamber, and bearings are outside the scope of this paper. Discussion of the armature, rotor, and stator follows below.

Figure 3 shows the cross-section of the machine with main components. The stator core is axially split into two equal parts and the superconducting excitation coil is sandwiched between them. The stator core is constructed using laminated magnetic steel. Sections 3 and 8 detail the lamination directions and the unconventional magnetic flux path these must support. Armature coil sides are shown laid axially on the stator. High rotational frequency combined necessitates the rotor be machined from a single piece, and the rotor's role in augmenting the magnetic field supplied by the exciter coil requires this piece to be magnetic steel. In Figure 3 the rotor is shown with one solid-pole (on the right) and one void-pole (on the left) aligned with stator core-the void pole is located at the mid-point between two adjacent solid-poles on the rotor and represents the part of the rotor volume where minimum magnetic flux is supported, i.e., where there is no magnetic steel.

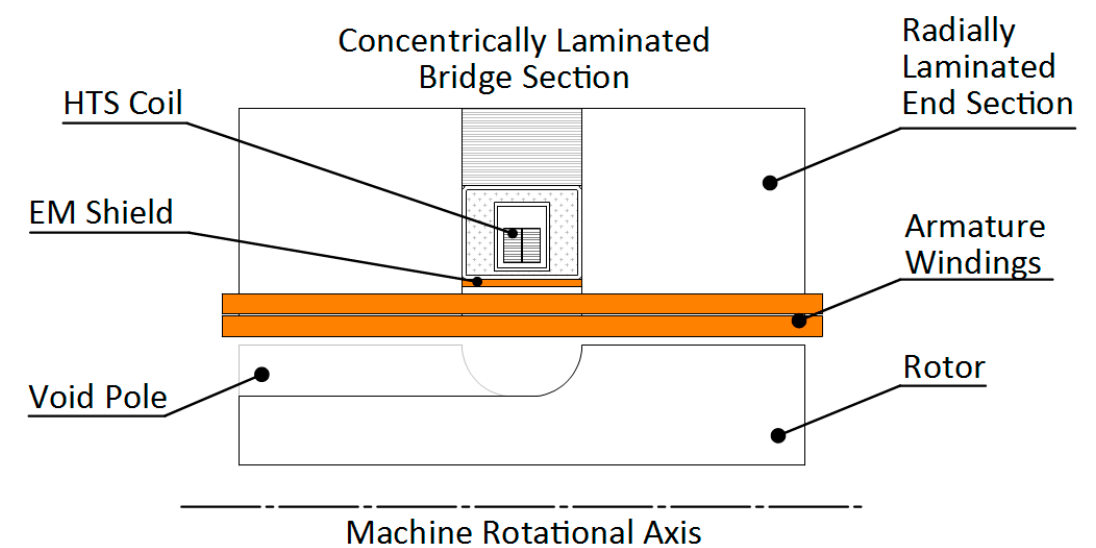

Figure 3. Schematic cross-section of stator and rotor layout. A detailed image of the superconducting coil is shown in Figure 10.

\section{Sizing Analysis}

A 2D approximation of the machine as shown in Figure 4, is utilized for sizing analysis with 2D FEA. In this approximation the rotor poles are not offset by 90 degrees as the behavior of interest is the capability of the machine to effectively route flux within the rotor and stator. Two kinds of armature windings were considered; (a) coils in air-gap, and (b) coils in slots in the iron core. 


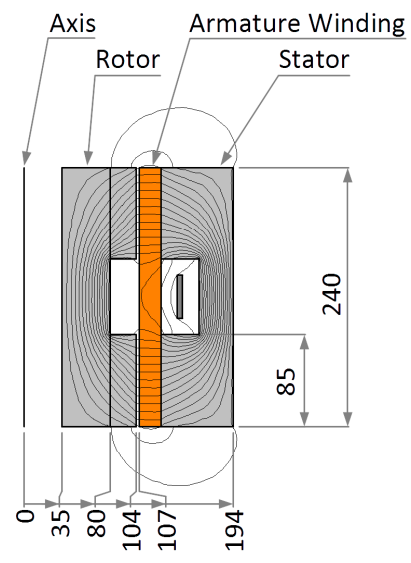

(a)

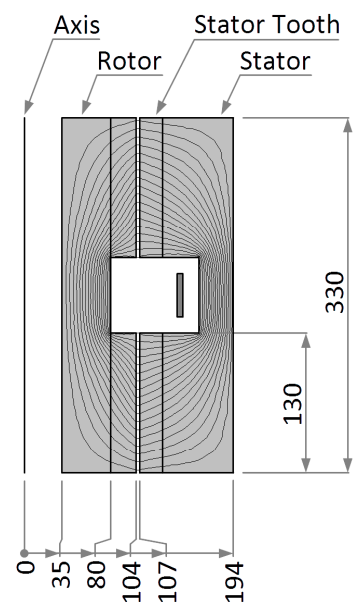

(b)

Figure 4. Representative cross-sections of the air-gap (a) and iron-slot (b) armature coils showing flux distribution as calculated using 2D FEA software FEMM [19]. Only (a) shows the armature windings as the section taken in (b) passes through the stator tooth (all dimensions in $\mathrm{mm}$ ).

Figure 4a shows a cross-section with armature coils residing in the gap between the stator and rotor, i.e., there are no stator iron teeth. Although a variety of armature winding configurations are possible, a unique single-layer (SL) winding design is considered for this study. The dimensions of this cross-section have been selected to suit the specifications of Table 1.

Likewise, Figure $4 \mathrm{~b}$ shows the cross-section with armature coils housed between iron stator teeth. A double-layer (DL) winding configuration is selected here. The radial depth of the armature coils is same as for the air-gap winding coils (Figure 4a).

In each of these simulations the stator and rotor are taken to be unlaminated 1020 steel with non-linear BH curve saturating at approximately $2.8 \mathrm{~T}$. Each representative cross-section considers the shaft material to be air and the rotor has been sized so as not to require the shaft to be part of the magnetic circuit. Although the design of a functional generator which supplies alternating current at the stator windings requires a non-symmetric lobed rotor, the 2D approximations used for sizing are axisymmetric as the total magnetic flux is not affected by the asymmetry.

The location of the field excitation coil is identical in both cases. However, $1 / 2$ the active length of iron core is longer for the DL design ( $85 \mathrm{~mm}$ for SL versus $130 \mathrm{~mm}$ for DL). Armature coils for both SL and DL designs employ liquid cooling. The two possible winding configurations are shown in Figure 5. The lightweight SL layout on the left, and the more conventional DL layout on the right. The coil colors signify the three phases.

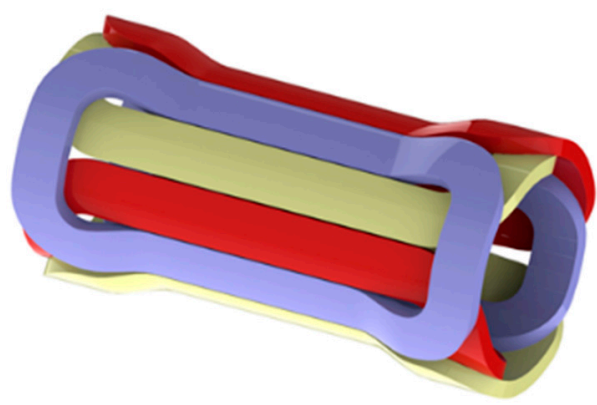

(a)

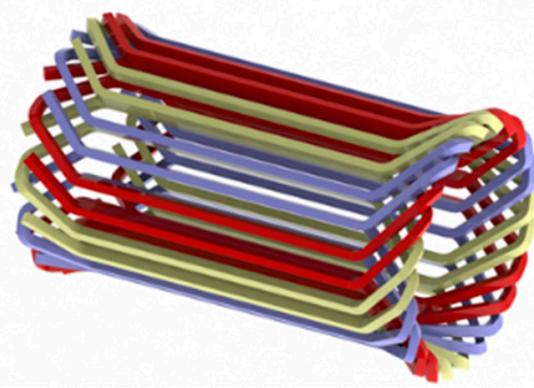

(b)

Figure 5. Armature windings, (a) single layer (SL) and (b) double layer (DL).

Harmonic content in the terminal voltage for the two types of windings is shown in Figure 6. Overall, both SL and DL designs have similar harmonic contents. The 3rd, 9th, and 15th harmonics 
cancel out in a three-phase system. The 5th and 7th harmonics are larger for SL than DL design, but the 11th and 13th harmonics are smaller for the SL than the DL design. Nevertheless, harmonic contents in both designs appears to be within an acceptable range. However, during detailed design phase, poles will be shaped further to reduce harmonic contents, just as is customary for salient pole synchronous machines.

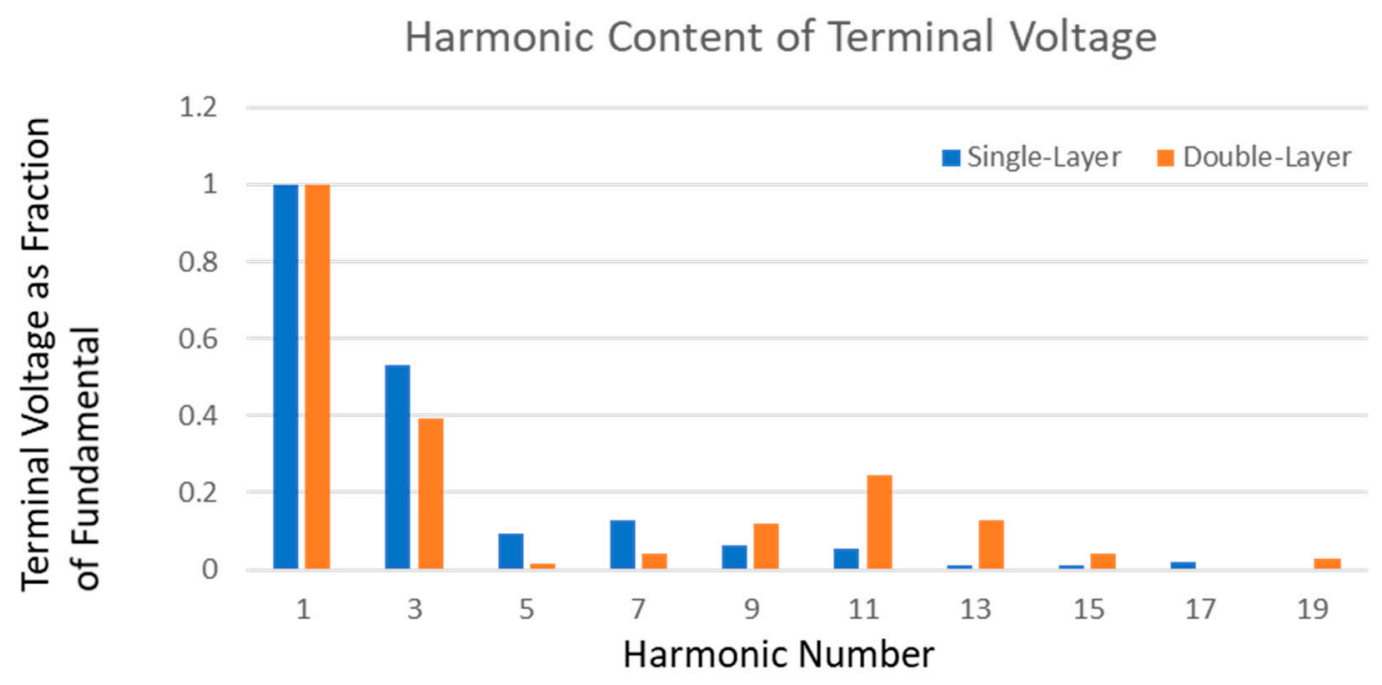

Figure 6. Harmonic content in the terminal voltage of SL and DL designs.

The 2D representations presented in Figure 4 each display a single magnetic circuit enclosing the cross-sectioned superconducting exciter coil. As current in the coil travels into the page the magnetic flux travels around the coil in a clockwise direction, i.e., vertically upward through the rotor, to the left at the upper rotor lobe and into the stator, vertically downward through the stator, then to the right to re-enter the rotor at the lower rotor lobe. This $2 \mathrm{D}$ approximation was used in sizing the required iron components, however if the rotor lobes were aligned in this way the stator windings would experience zero net change in magnetic field along their length as the lobes passed.

To ensure the stator windings experience an alternating magnetic field the rotor lobes are rotationally offset by 90 degrees, as illustrated in Figure 1 and below in Figure 7. This twists the magnetic circuit so each stator winding experiences a changing net magnetic field as the rotor lobes pass. The idealized magnetic circuit flux path is illustrated in red in Figure 7. This path travels azimuthally through the central "bridge" section of the stator as supported by the concentric laminations of this part of the stator (Figure 3).

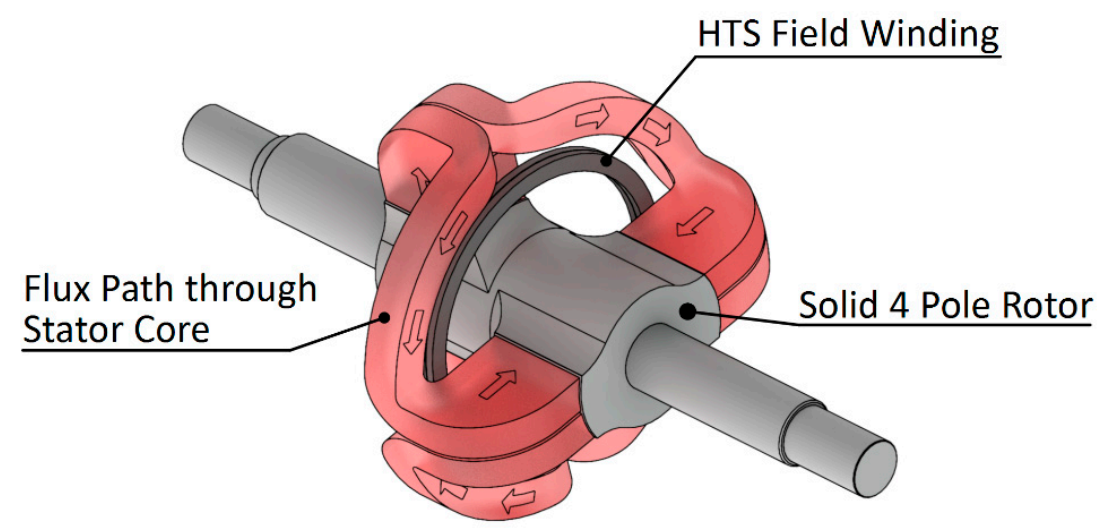

Figure 7. Illustration of the idealized flux pattern through the stator (in red), relative to the rotor. The flux path is closed through the rotor (light grey) and encircles the field coils (dark grey). 
Omitted from Figure 7 for clarity, a small portion of flux lines also cross through the void-pole to the stator core. Each half of the stator core experiences maximum magnetic field under a solid-pole and minimum under a void-pole. Nevertheless, field under all pole, facing each $\frac{1}{2}$ stator core is unidirectional.

Coils with straight sides (spanning the whole stator core) are employed for armature winding located in the stator. Figure 4 shows the flux contours when each of the two configurations is salient. In this approximation the rotor poles are aligned with the stator core. This approximation is used for calculating the flux leakage through the interpole regions and stator. At any instant, an armature coil experiences maximum flux linkage $\left(\Phi_{\max }\right)$ in the part of the stator aligned with the rotor pole, and minimum flux linkage $\left(\Phi_{\min }\right)$ in the part of the stator aligned with the void pole. The net flux linkage $\left(\Phi_{\mathrm{o}}\right)$ is the difference between these two values. The FEA code is utilized for calculating flux linkages in each half of the core. The net flux linkages are utilized for calculating induced voltage in a coil. Furthermore, location of $\Phi_{\max }$ is identified as d-axis (solid-pole) and location of $\Phi_{\min }$ is identified as q-axis (void-pole). The design analysis then assumes that the whole machine is represented by a half-core being acted upon by complete set of $\mathrm{d}$ - and q- poles, with $\Phi_{\mathrm{o}}$ being experienced under each pole. On this basis, the induced voltage in an armature coil is as in Equation (1):

$$
\mathrm{E}_{\mathrm{o}}=\mathrm{c} \cdot \Phi_{\mathrm{o}} \cdot \omega_{\mathrm{o}}
$$

where:

$\mathrm{E}_{\mathrm{O}}=$ induced voltage $/$ coil $(\mathrm{V})$

$\mathrm{C}=$ proportionality constant

$\Phi_{\mathrm{o}}=$ net flux linkage with a coil $(\mathrm{Wb})$

$\omega_{\mathrm{o}}=$ rotational frequency $(\mathrm{rad} / \mathrm{s})$

The excitation field coil is circular in shape which makes it simple for construction. It is sized to provide necessary ampere-turns for excitation of the armature coils. The SL design has a larger effective air gap between the rotor and stator as it does not include iron teeth, this necessitates more ampere-turns than what is required in the DL design. Since this coil is sandwiched between two halves of stator iron core, it does not experience magnetic forces due to interaction with the armature winding current. Figure 3 shows cross-section of the machine with locations of armature and field excitation coils. However, excitation coil side facing the armature winding experiences AC field due to currents in the armature coils. It is essential that this AC field be sufficiently attenuated for minimizing AC losses in the excitation coil. This is achieved by creating a separation between armature coils and excitation coils and installing an EM shield (copper or aluminum) to attenuate AC field experienced by the field coil. The location of the EM shield is identified in the Figure 3. In this design analysis, the excitation coil employs ReBCO superconductor.

Preliminary design of the machines employing SL and DL armature windings are summarized in Table 2. Both machines are sized to generate $500 \mathrm{~kW}$ at a three-phase line voltage of 830-900 V. Total ampere-turns needed for SL design are much larger than DL design due to significantly larger air gap in the SL design - this results in more turns in the field coil for SL design than the DL design. The SL machine is shorter in overall length and lighter than the DL machine. However, the DL machine is more efficient than the SL machine and uses much shorter length of ReBCO wire (185 m for SL versus $54 \mathrm{~m}$ for DL). This makes DL machine less costly to build than the SL machine. The table also lists preliminary component weights for the two machines; The DL machine weighs $27 \%$ more than the SL machine.

The DL design is preferable over the SL design if size and weight are not of concern. In the subway energy storage applications, the heavier, more efficient DL design is desirable as the motor is ground based at the subway station, sufficient space is available for the larger machine size, and high efficiency is desirable. For this machine design the superconducting material is the largest single component cost. In the SL design the expected superconductor cost is $\$ 39,000$, while in the DL 
design much less superconductor is required, bringing the cost of the superconductor down to $\$ 4400$. The superconductor cost for the SL design constitutes a large fraction of total expected cost of the machine, $\$ 100,000$. The DL design is significantly more cost effective. Only the machine design employing the DL stator with ReBCO field coil is discussed further.

Table 2. Preliminary design summary for SL and DL machines.

\begin{tabular}{|c|c|c|}
\hline Parameter & Single Layer & Double Layer \\
\hline Power Rating, MVA & 524 & 540 \\
\hline Output power at full-load, MW & 519 & 535 \\
\hline Line voltage, V-rms & 900 & 866 \\
\hline Phase current, A-rms & 336 & 360 \\
\hline Overall axial length, $\mathrm{m}$ & 0.32 & 0.46 \\
\hline Overall diameter, $\mathrm{m}$ & 0.44 & 0.44 \\
\hline Mass of the machine alone, $\mathrm{kg}$ & 345 & 467 \\
\hline Mass of cryo-cooling system, $\mathrm{kg}$ & 30 & 49 \\
\hline Total mass, kg & 375 & 516 \\
\hline Efficiency at full-load, \% & 98.9 & 99.2 \\
\hline Cryocooler load, kW & 0.80 & 1.36 \\
\hline \multicolumn{3}{|l|}{ Other Parameters of Interest } \\
\hline Rated speed, RPM & 25,000 & 25,000 \\
\hline Number of pole & 4 & 4 \\
\hline Frequency, $\mathrm{Hz}$ & 833 & 833 \\
\hline \multicolumn{3}{|l|}{ FIELD WINDING DETAILS } \\
\hline Number of turns & 204 & 24 \\
\hline Field winding current, A & 252 & 317 \\
\hline Field winding Io/Ic ratio & 0.54 & 0.49 \\
\hline HTS wire width, mm & 3 & 3 \\
\hline HTS wire length, m & 185 & 22 \\
\hline \multicolumn{3}{|l|}{ STATOR WINDING DETAILS } \\
\hline Active length under each pole, $\mathrm{mm}$ & 85 & 130 \\
\hline Number of armature turns/ph & 20 & 8 \\
\hline Number of coils in armature & 6 & 24 \\
\hline Number of turns/race coil & 1 & 1 \\
\hline \multicolumn{3}{|l|}{ Machine component weight summary } \\
\hline Shaft, kg & 4 & 4 \\
\hline Rotor yoke, $\mathrm{kg}$ & 42 & 59 \\
\hline Poles, $\mathrm{kg}$ & 7 & 12 \\
\hline Stator case, $\mathrm{kg}$ & 144 & 178 \\
\hline Cooling system, $\mathrm{kg}$ & 30 & 49 \\
\hline Total machine mass, $\mathrm{kg}$ & 345 & 467 \\
\hline Total system mass, $\mathrm{kg}$ & 375 & 516 \\
\hline Torque density, N/kg & 533 & 388 \\
\hline
\end{tabular}

\section{Armature Design}

Armature design employs single turn coils with embedded cooling tube. A Litz wire turn with an embedded cooling tube is shown in Figure 8. The overall cross-section of each turn is $10 \mathrm{~mm} \times 12 \mathrm{~mm}$ and the stainless-steel tube at the center has a diameter of $5 \mathrm{~mm}$. The total cross-section of the Litz cable is equivalent to that of a single AWG 1/0 conductor. Table 3 provides more details, including data from the New England Wire catalogue. 


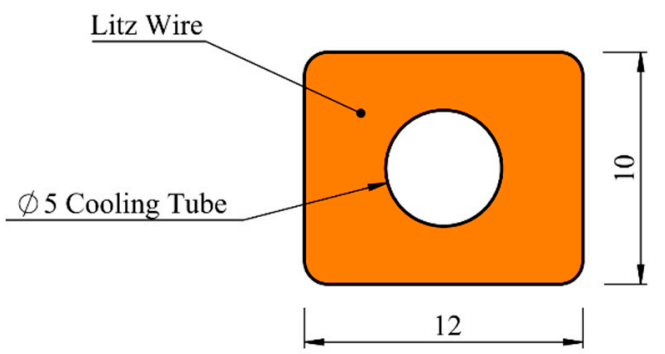

Figure 8. Coil turn cross-section with an embedded cooling tube (dimensions in $\mathrm{mm}$ ).

Table 3. Litz wire parameters.

\begin{tabular}{cc}
\hline Parameter & Value \\
\hline Space available for Litz, $\mathrm{mm}^{2}$ & 100 \\
Equivalent AWG size & $1 / 0$ \\
Strand diameter, $\mathrm{mm}$ & 0.32 \\
Number of strands & 665 \\
Copper cross-section, $\mathrm{mm}^{2}$ & 54 \\
Resistance of cable, Ohm $/ \mathrm{m}$ & 0.00035 \\
Resistive loss per coil, $\mathrm{W}$ & 51 \\
Cooling tube diameter, $\mathrm{mm}$ & 5 \\
Water flow velocity, $\mathrm{m} / \mathrm{s}$ & 1 \\
Pressure drop over two coils in series, kPa & 6.7 \\
Difference in cooling tube wall and water temperature, $\mathrm{K}$ & 0.34 \\
Temperature rise of water through 2 coils in series, $\mathrm{K}$ & 1.24 \\
\hline
\end{tabular}

Only 6.7 kPa pressure drop is experienced for a sustained water flow rate of $1 \mathrm{~m} / \mathrm{s}$ in a tube length $(2.3 \mathrm{~m})$ equal to two coils connected in series. The water temperature rise is about $1.2 \mathrm{~K}$. Based on this data, it looks feasible that all coils of a phase could be connected in series to form a single cooling circuit for each phase. A wave shape winding arrangement, shown in Figure 9, is selected as it enables construction of all coils of a phase using a single length of cable. The total resistive loss in all armature coils is $1.2 \mathrm{~kW}$ while carrying the rated load.

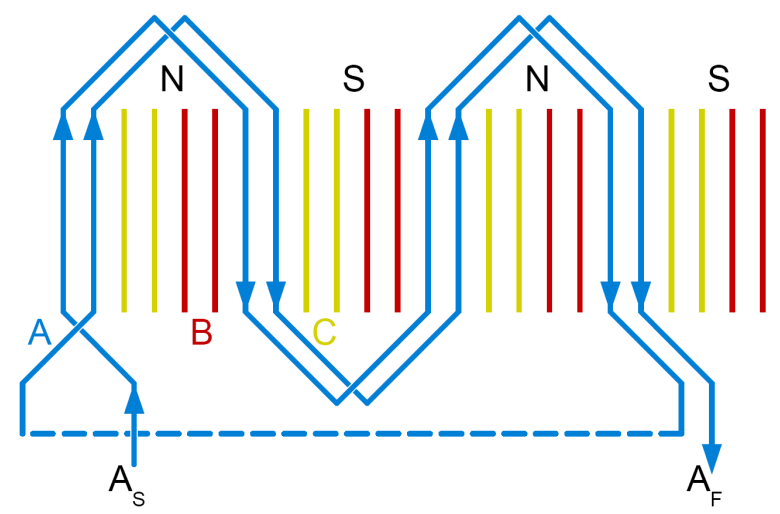

Figure 9. Phase-A coils connected in a wave fashion for four pole-pitches.

\section{Superconducting Excitation Coil Design}

The superconducting excitation coil employs ReBCO wire cooled to $50 \mathrm{~K}$. The coil is housed in a stainless-steel cryostat and surrounded by multi-layer-insulation (MLI) foil as shown in Figure 10. To reduce thermal conduction the cryostat is not mounted to the stator but rather mounted to the vacuum chamber housing via insulated support rods that protrude through ports in the stator. Between the cryostat wall and the stator body is a copper EM shield [20]. It is designed to protect the superconductor from the alternating field due to current in the armature windings. It is attached on to 
the room-temperature bore side of cylindrical cryostat box. Any losses in it are removed using the means employed for cooling the room-temperature surface of the cryostat.

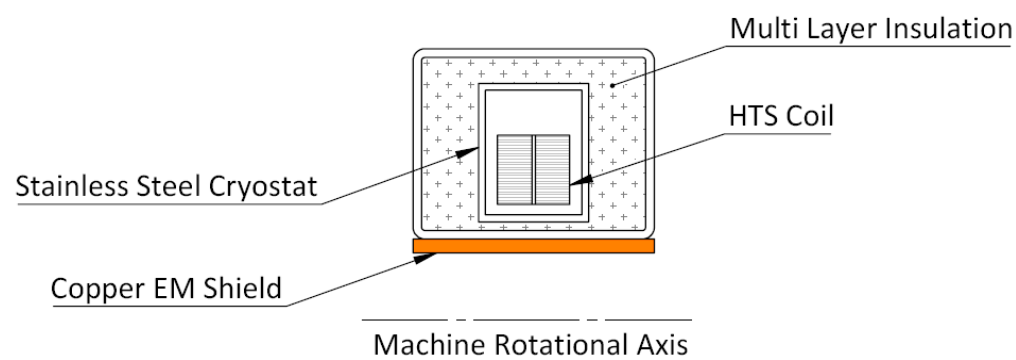

Figure 10. Schematic cross-section of HTS excitation coil cryostat. The HTS coil consists of two 12 turn ReBCO coils which remain static while magnetizing the rotating solid steel rotor.

The field winding, made of ReBCO, has 24 turns. It carries $317 \mathrm{~A}$ when the machine is operating at full-load. A different superconductor could be used for generating the total amp-turns equal or greater than 7600 ( 24 turns * $317 \mathrm{~A})$. Furthermore, the ratio of operating-current/critical-current $\left(I_{o} / I_{c}\right)$ for the superconductor is preferred to be less than or equal to $\sim 50 \%$. Current leads for the superconducting coil provide a path for thermal conduction from room-temperature to the cold environment of the superconducting coil, and require the exciter circuit to include non-superconducting elements which generate heating through ohmic losses. This thermal load is estimated to be $\sim 25 \mathrm{~W}$. A contactless exciter concept is available [21] that could charge the excitation coil without physical current leads spanning room-temperature and cryogenic environments, while enabling the exciter circuit to be almost entirely superconducting. With this exciter implemented, it would be possible to operate the flywheel continuously with a smaller cooling system as the conduction and ohmic heating loads are greatly reduced.

\section{Rotor Design}

Figure 11 shows a three-dimensional view of the rotor. This configuration creates a four-pole field pattern as viewed from each half of the stator core. The rotor is manufactured from one solid piece of Carpenter Technology Corporation, Philadelphia, USA, Aermet 310 magnetic steel or similar and shrink-fit onto the steel shaft. The diameter is selected based on the structural strength of selected rotor material. The rotor body between the two sets of solid-poles carries the flux from solid-poles on the left to the solid-poles on right, this magnetic circuit is completed right to left through the stator, surrounding the exciter coils (Figure 7). The flux within the rotor is essentially DC therefore saturation of the rotor body is permissible.

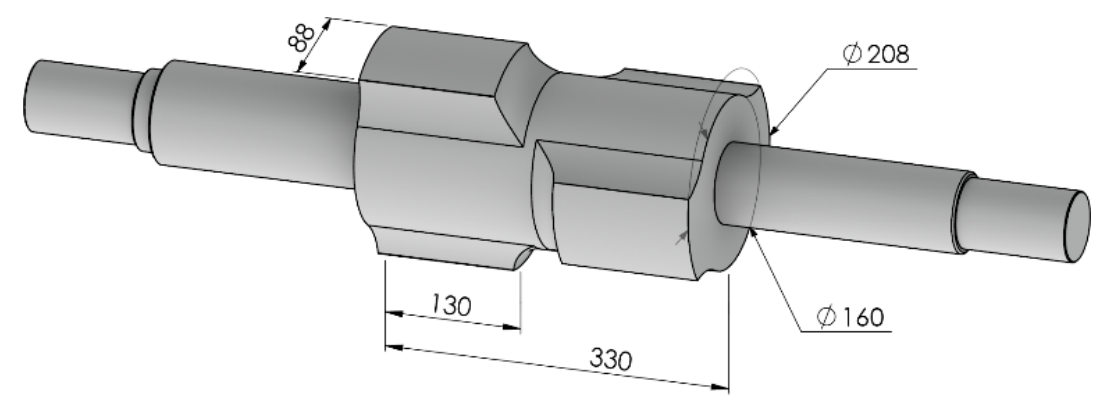

Figure 11. An isometric view of the solid rotor body on a shaft (all dimensions in $\mathrm{mm}$ ).

\section{Stator Design}

Figure 12 shows the arrangement of stator laminations. The end sections are radially laminated, while the bridge section is concentrically laminated, e.g., like paper wound onto a scroll. Armature 
coils span the stator laminations parallel to the rotational axis. In the DL machine the armature windings are housed in the stator lamination teeth. The exciter coil is located between end sections and inside the bridge section as shown in Figure 1. The selected core material is the JFE Steel 10JNEX900. This material is available in $0.1 \mathrm{~mm}$ thickness. The core loss is $10 \mathrm{~W} / \mathrm{kg}$ in $1 \mathrm{~T}$ field and $1 \mathrm{kHz}$ frequency. Its saturation magnetic field is $1.8 \mathrm{~T}$.

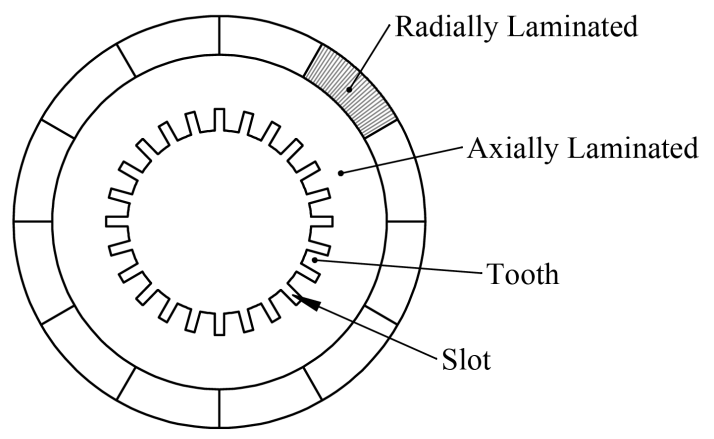

Figure 12. Arrangement of stator end section laminations.

The end sections are constructed of an axially laminated core block surrounded by radially laminated ring segment blocks. Slots and teeth are cut into an axially laminated core, as commonly found in conventional machine cores. On the outside perimeter of this core, circular segments make up balance.

\section{Performance Parameters}

Table 4 includes parameters necessary for calculating machine performance under different loads and operating conditions as well as for interfacing it with inverters. Parameters are expressed in per-unit values; referenced to a base impedance of $1.39 \mathrm{ohm}$. Synchronous reactance of this machine is low due to the larger air-gap between rotor and stator. Small synchronous reactance is usually beneficial for stable operation of the machine on an electric grid. However, the small value also creates very large fault current during sudden short-circuit of the stator winding. Attention needs to be paid to this aspect during inverter design. No-load and full-load field currents are $278 \mathrm{~A}$ and $317 \mathrm{~A}$, respectively. The field winding should be designed to carry $317 \mathrm{~A}$ with an Ic/Io of about 2 . However, it must be noted that if the machine operating at full-load suddenly loses load, the armature voltage will rise to $1.14 \mathrm{pu}(=866 \times 1.14=987 \mathrm{~V}$-rms $)$. Since it is difficult to change HTS field winding current rapidly, it would be necessary to modulate the voltage electronically in the inverter. In the event of a quench of the superconducting field winding, it would be necessary to extract its magnetic stored energy as rapidly as possible. The field winding will be shorted at its terminal through a $0.32 \Omega$ discharge resistor-the maximum voltage imposed (during the discharging operation) on the field winding is limited to $100 \mathrm{~V}$. The time constant for the discharge current is $3.0 \mathrm{~ms}$.

Table 5 summarizes performance data for the machine calculated using $2 \mathrm{D}$ finite element analysis. The performance has been calculated for a full-load current of $360 \mathrm{~A}$ at a power-factor of 0.99 lagging. A more accurate value for power-factor would be based on the inverter design but the value selected here is conservative. The load angle with respect to the terminal voltage is $1.34^{\circ}$, which is quite small. However, in absence of a fixed terminal voltage, the value of load angle is of little interest.

The nominal shaft torque for the machine is $208 \mathrm{Nm}$. But during short-circuit at the machine terminals, the torque will increase to $1487 \mathrm{Nm}$. Thus, it would be necessary to design the rotor shaft and the armature winding mechanical support to bear this torque with an acceptable safety margin, e.g., a safety factor of at least 2. Attractive forces between rotor and stator are $9282 \mathrm{~N}$ under a solid-pole and $246 \mathrm{~N}$ under the void-pole. 
Table 4. Machine parameters at rated frequency $(833 \mathrm{~Hz})$.

\begin{tabular}{cc}
\hline Parameters & Value \\
\hline Rated line voltage, $\mathrm{V}$ & 866 \\
Rated current, A & 360 \\
Power rating, $\mathrm{kVA}$ & 540 \\
Base impedance, $\Omega$ & 1.39 \\
D-axis synchronous reactance, pu & 0.14 \\
Q-axis synchronous reactance, pu & 0.02 \\
Armature resistance, pu & 0.0023 \\
Induced voltage with pf = 1 load, pu & 1.14 \\
Field current-no-load, A & 278 \\
Field current-full-load, A & 317 \\
Field winding inductance, mH & 0.96 \\
Maximum field winding discharge voltage, V & 100 \\
Resistance of field winding discharge resistor, $\Omega$ & 0.32 \\
Field winding discharge time constant, ms & 3.0 \\
Mutual inductance between Field and Armature, $\mathrm{H}$ & $6.29 \times 10^{-5}$ \\
\hline
\end{tabular}

Table 5. Calculated performance.

\begin{tabular}{cc}
\hline Performance & Value \\
\hline Rated line voltage, $\mathrm{V}$ & 866 \\
Rated current, A & 360 \\
Power rating, kVA & 540 \\
Field current-no-load, A & 278 \\
Power factor at full-load-lagging & 0.99 \\
Field current-full-load, A & 317 \\
Load angle at full-load, deg & 1.3 \\
Induced voltage at full-load, pu & 1.14 \\
Power generated at full-load, pu & 1.01 \\
Torque on armature at full-load, Nm & 208 \\
Torque on armature during a short-circuit, Nm & 1487 \\
Attractive force between rotor and stator & \\
Under a salient pole, N & 9282 \\
Under non-salient pole, N & 246 \\
\hline Losses at Full-load & Value \\
\hline Stator iron core loss, $\mathrm{kW}$ & 1.7 \\
Armature resistive loss, $\mathrm{kW}$ & 1.2 \\
Armature cooling system power, kW & 0.13 \\
Field winding cooler power, kW & 1.37 \\
Total losses at full-load, $\mathrm{kW}$ & 21 \\
Efficiency at full-load, $\%$ & 4.45 \\
Total losses at no-load, $\mathrm{kW}$ & 99.2 \\
\hline & 3.23 \\
\hline
\end{tabular}

The Table 5 also lists different loss components when the machine is carrying full-load. Stator core loss and armature winding resistive loss are two significant components. Cryogenic cooling system power is estimated to be $1.37 \mathrm{~kW}$ based on a refrigerator coefficient of performance (COP) of 21 at $50 \mathrm{~K}$ (COP is the ratio of power input to refrigerator to the heat power removed by the refrigerator). This COP value is obtained from Yuki Iwasa (MIT) book, 2nd Edition [22]. A cooler system selected by a manufacturer may have different COP. Furthermore, thermal load calculations for the HTS coil might be different as they are a function of HTS coil type, its construction and interface with the room-temperature systems. Based on the assumptions made here, total loss at full-load is $4.4 \mathrm{~kW}$, which yields an efficiency of $99.2 \%$. This looks attractive at this conceptual design process and could be used as a goal to strive for. 
It must be noted that this machine experiences significant losses under no-load operation. For example, if the field current is kept at its full-load operating value, the machine thermal load (cryo-cooler power) and core loss will remain unchanged and total loss would be $3.2 \mathrm{~kW}$. However, if the field current is turned off during a prolonged no-load operation then the only loss component (cryo-cooler power loss) would be less than $1.36 \mathrm{~kW}$. Thus, it would be necessary to turn off the field current when the flywheel is turning and storing energy for a long period of time. With contactless current transfer to the HTS coil, the above-mentioned $1.36 \mathrm{~kW}$ loss would be reduced to $30 \%(\sim 0.4 \mathrm{~kW})$.

\section{Summary}

For application of a ground-based fast energy storage system the DL concept looks attractive as compared with the SL design, which is more expensive due to the longer length of superconductor needed for the field winding. The DL solution is manufacturable using existing methods and technology, which will result in reduced construction time and cost, as well as shorter development time. The analysis presented here is based on employing ReBCO field coils, however, the comparison is equally valid for lower cost DI-BSCCO coils. DI-BSCCO coils are a commercially available technology with potential for further reducing development and construction time and cost. The concept design presented here is similar to a superconducting machine built and tested by General Electric [16] and, therefore, the authors are sure about the feasibility of the presented machine. One of the authors was also part of a team that built and tested such a machine in about 1978 using copper field windings.

The design of a complete flywheel system suitable for fast energy recovery and delivery presents several challenges not within the scope of this paper. Magnetic bearings will be required to support the high rotational frequencies, as will a machine enclosure capable of holding partial vacuum to prevent significant windage losses. Design and development of flywheels and the machine shaft also present several challenges relating to the high rotational frequencies.

We are currently working towards manufacturing a demonstrator DL homopolar motor. As part of this process we will address flywheel construction and magnetic bearing design including the potential to use passive superconducting bearings.

\section{Patents}

BADCOCK, Rodney Alan; HAMILTON, Kent Anthony; KALSI, Swarn Singh. 'Flywheel Energy Storage System.' CHN.Patent ZL 2017210288283, June 1, 2018.

BADCOCK, Rodney Alan; HAMILTON, Kent Anthony; KALSI, Swarn Singh. 'Flywheel Energy Storage system.' PCT Application PCT/NZ2018/050093.

Author Contributions: Conceptualization of the electrical machine: S.K.; conceptualization of the flywheel integration: R.A.B.; conceptualization of the integrated vacuum-contained flywheel system: K.H.; validation: S.K., R.A.B., and K.H.; formal analysis: S.K.; resources: Robinson Research Institute; writing-original draft preparation: S.K., R.A.B., and K.H.; writing—review and editing: S.K., R.A.B., K.H., and R.G.B.; visualization: K.H.; supervision: R.A.B.; project administration: R.A.B.; funding acquisition: R.A.B.

Funding: This research was funded by the New Zealand Ministry of Business Innovation and Employment grant number RTVU1707.

Acknowledgments: The authors wish to acknowledge the invaluable advice and assistance provided by James Storey and Chris W Bumby.

Conflicts of Interest: The authors declare no conflict of interest.

\section{References}

1. Bumby, J. Superconducting Rotating Electrical Machines; Clarendon Press: Oxford, UK, 1983.

2. Haran, K.; Kalsi, S.; Arndt, T.; Karmaker, H.; Badcock, R.; Buckley, B.; Haugan, T.; Izumi, M.; Loder, D.; Bray, J.W.; et al. High power density superconducting rotating machines-Development status and technology roadmap. Supercond. Sci. Technol. 2017, 30, 123002. [CrossRef] 
3. Arumugam, P.; Xu, Z.; La Rocca, A.; Vakil, G.; Dickinson, M.; Amankwah, E.; Hamiti, T.; Bozhko, S.; Gerada, C.; Pickering, S. High-Speed Solid Rotor Permanent Magnet Machines: Concept and Design. IEEE Trans. Transp. Electrif. 2016, 2, 391-400. [CrossRef]

4. Fleshler, S.; Buczek, D.; Carter, B.; Cedrone, P.; DeMoranville, K.; Gannon, J.; Inch, J.; Li, X.; Lynch, J.; Otto, A.; et al. Scale-up of $2 \mathrm{G}$ wire manufacturing at American Superconductor Corporation. Phys. C 2009, 469, 1316-1321. [CrossRef]

5. Karmaker, H.; Sarandria, D.; Ho, M.; Feng, J.; Kulkarni, D.; Rupertus, G. High-Power Dense Electric Propulsion Motor. IEEE Trans. Ind. Appl. 2015, 51, 1341-1347. [CrossRef]

6. Madavan, N.; Del Rosario, R.; Jankovsky, A. Hybrid-Electric and Distributed Propulsion Technologies for Large Commercial Transports: A NASA Perspective. NASA Technical Report ARC-E-DAA-TN2723 Document 20160000589. Available online: https:/ / ntrs.nasa.gov / search.jsp?R=20160000589 (accessed on 28 December 2018).

7. Barnes, P.; Rhoads, G.; Tolliver, J.; Sumption, M.; Schmaeman, K. Compact, lightweight, superconducting power generators. IEEE Trans. Magn. 2005, 41, 268-273. [CrossRef]

8. Jansen, R.; Brown, G.; Felder, J.; Duffy, K. Turboelectric Aircraft Drive Key Performance Parameters and Functional Requirements. In Proceedings of the 51st AIAA/SAE/ASEE Joint Propulsion Conference, Orlando, FL, USA, 27-29 July 2015.

9. Daoud, M.; Abdel-Khalik, A.; Elserogi, A.; Ahmed, S.; Massoud, A. Flywheel Energy Storage Systems. Handb. Clean Energy Syst. 2015, 1-14. [CrossRef]

10. Vazquez, S.; Lukic, S.; Galvan, E.; Franquelo, L.; Carrasco, J. Energy Storage Systems for Transport and Grid Applications. IEEE Trans. Ind. Electron. 2010, 57, 3881-3895. [CrossRef]

11. Amiryar, M.; Pullen, K. A Review of Flywheel Energy Storage System Technologies and Their Applications. Appl. Sci. 2017, 7, 286. [CrossRef]

12. Pena-Alzola, R.; Sebastian, R.; Quesada, J.; Colmenar, A. Review of flywheel based energy storage systems. In Proceedings of the 2011 International Conference on Power Engineering, Energy and Electrical Drives, Malaga, Spain, 11-13 May 2011.

13. Buchroithner, A.; Wegleiter, H.; Schweighofer, B. Flywheel Energy Storage Systems Compared to Competing Technologies for Grid Load Mitigation in EV Fast-Charging Applications. In Proceedings of the 2018 IEEE 27th International Symposium on Industrial Electronics (ISIE), Cairns, Australia, 13-15 June 2018.

14. Tsao, P.; Senesky, M.; Sanders, S. A synchronous homopolar machine for high-speed applications. In Proceedings of the Conference Record of the 2002 IEEE Industry Applications Conference. 37th IAS Annual Meeting (Cat. No.02CH37344), Pittsburgh, PA, USA, 13-18 October 2002.

15. Lee, J.; Park, S.; Kim, Y.; Lee, S.; Kim, W.; Choi, K.; Hahn, S. Electrical Properties Analysis and Test Result of Windings for a Fully Superconducting $10 \mathrm{HP}$ Homopolar Motor. IEEE Trans. Appl. Supercond. 2012, 22, 5201405.

16. Sivasubramaniam, K.; Zhang, T.; Lokhandwalla, M.; Laskaris, E.; Bray, J.; Gerstler, B.; Shah, M.; Alexander, J. Development of a High Speed HTS Generator for Airborne Applications. IEEE Trans. Appl. Supercond. 2009, 19, 1656-1661. [CrossRef]

17. Carpenter-CarTech®AerMet ${ }^{\circledR 3} 10$ Alloy. Available online: https://www.cartech.com/en/productsolutions / cartech-aermet-310-alloy/ (accessed on 28 December 2018).

18. Mukoyama, S.; Nakao, K.; Sakamoto, H.; Matsuoka, T.; Nagashima, K.; Ogata, M.; Yamashita, T.; Miyazaki, Y.; Miyazaki, K.; Maeda, T.; et al. Development of Superconducting Magnetic Bearing for $300 \mathrm{~kW}$ Flywheel Energy Storage System. IEEE Trans. Appl. Supercond. 2017, 27, 1-4. [CrossRef]

19. Meeker, D. Finite Element Method Magnetics. Available online: http://www.femm.info/ (accessed on 28 December 2018).

20. Badcock, R.A.; Hamilton, K.A.; Kalsi, S.S. Flywheel Energy Storage System. China Patent ZL 2017 2 1028828.3, 1 June 2018.

21. Hamilton, K.; Pantoja, A.; Storey, J.; Jiang, Z.; Badcock, R.; Bumby, C. Design and Performance of a "Squirrel-Cage" Dynamo-Type HTS Flux Pump. IEEE Trans. Appl. Supercond. 2018, 28, 1-5. [CrossRef]

22. Iwasa, Y. Case Studies in Superconducting Magnets, 2nd ed.; Springer: Boston, MA, USA, 2009.

(C) 2018 by the authors. Licensee MDPI, Basel, Switzerland. This article is an open access article distributed under the terms and conditions of the Creative Commons Attribution (CC BY) license (http:/ / creativecommons.org/licenses/by/4.0/). 